\title{
Summer survey of fur seals at Prince Edward Island, southern Indian Ocean
}

\author{
MN Bester ${ }^{1 *}$, PG Ryan² and J Visagie ${ }^{3}$ \\ ${ }_{1}^{1}$ Mammal Research Institute, Department of Zoology and Entomology, University of Pretoria, Pretoria 0002, South Africa \\ 2 Percy FitzPatrick Institute, DST/NRF Centre of Excellence, University of Cape Town, Rondebosch 7701, South Africa \\ ${ }^{3}$ Cape Nature, Private Bag X29, Rondebosch 7701, South Africa \\ *Corresponding author, e-mail: mnbester@zoology.up.ac.za
}

Manuscript received June 2009; accepted August 2009

\begin{abstract}
The onshore distributions and the abundances of Antarctic fur seals Arctocephalus gazella and Subantarctic fur seals $A$. tropicalis were determined at Prince Edward Island during 16-20 December 2008. This repeats a survey conducted in December 2001 and extends the area surveyed to include the entire south-west coast of Prince Edward Island. Of the two colonies of Antarctic fur seals, the colony among Subantarctic fur seals north of Boggel Beach remained small, with increased numbers of Subantarctic fur seals and putative hybrids. The other Antarctic fur seal breeding colony at Penguin Beach remained free of Subantarctic fur seals and had expanded at a mean intrinsic rate of natural increase of $11.4 \%$ per year from 2001 . With an estimated 810 pups, the Antarctic fur seal is still in the rapid recolonisation phase of population growth. The distribution of the more widespread and abundant Subantarctic fur seals also had increased, with several new breeding colonies along the east coast and one at Kent Crater on the west coast. The annual pup production was conservatively estimated at 14130 pups. The mean intrinsic rate of natural increase has declined to $-0.3 \%$ per year over the last seven years, compared to the $9.3 \%$ per year between $1987 / 1988$ and 2001/2002, and the population is in the mature phase of population growth.
\end{abstract}

Keywords: Arctocephalus, distribution, fur seals, population increase, Prince Edward Island, Subantarctic

\section{Introduction}

Both the Antarctic fur seal Arctocephalus gazella and the Subantarctic fur seal $A$. tropicalis breed on the Prince Edward Islands in the southern Indian Ocean (Condy 1978), which comprise of Marion Island and Prince Edward Island (21 km apart). The history of sealing at the islands and population counts during the period of recovery subsequent to the cessation of sealing in 1931 are summarised in Kerley (1987), Bester et al. (2003) and Hofmeyr et al. (2006). Breeding of Antarctic fur seals at Prince Edward Island was first confirmed in 1975 (Condy 1978), but the late census dates confounded acceptable estimates of the number of births and the breeding population size during that time and the two subsequent attempts (Bester et al. 2003). In 2001, for the first time, the breeding population size and pup production for Antarctic fur seals at Prince Edward Island were determined and the available census figures updated for the Subantarctic fur seal (Bester et al. 2003). This study reports on further changes in the populations of both species present at Prince Edward Island, which fits within the objective of the Prince Edward Islands Management Plan (PEIMPWG 1996).

\section{Material and methods}

Prince Edward Island (44 km²; 46 $\left.38^{\prime} \mathrm{S}, 37^{\circ} 57^{\prime} \mathrm{E}\right)$ was visited from 16 to 21 December 2008. The fur seal survey was conducted on the north-western section (Ross Rocks Peninsula to Kent Crater) on 18 December, the south-western coast (Kent Crater to McNish Bay) on 19 December, and the south-eastern section (McNish Bay to Albatross Valley Beach) from 16 to 20 December (Figure 1). One inaccessible section of coastline, below the cliffs between Albatross Valley Beach and Ross Rocks Peninsula, could not be surveyed, as was the case in 2001 (Figure 1). However, the coast between Kent Crater and McNish Bay was scanned with binoculars from a series of vantage points along the top of the escarpment, which confirmed the absence of breeding fur seals in that area.

The census period represents the height of the breeding season haulout for Subantarctic fur seals (pupping spread over six weeks with a median pupping date of 18 December) and the end of the breeding/pupping season for Antarctic fur seals (pupping spread over three weeks with a median pupping date of 6 December) (Condy 1978, Kerley 1983, Hofmeyr et al. 2007). Aggregations of seals 


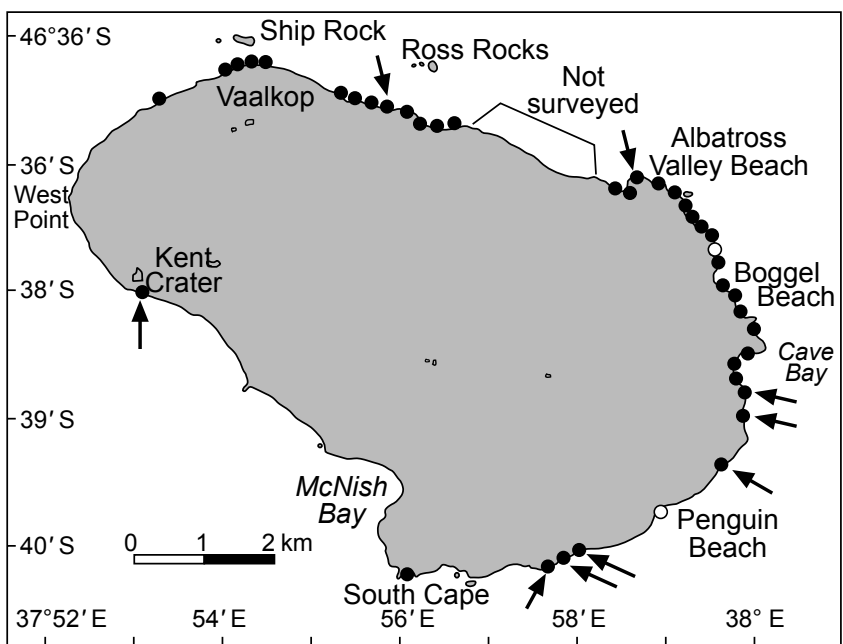

Figure 1: Prince Edward Island, showing the localities mentioned in the text, the main topographical features and the distribution of breeding colonies of $A$. tropicalis (closed circles) and $A$. gazella (open circles) during 2008. New A. tropicalis colonies are arrowed. The distribution of the numerous non-breeding and idle colonies of $A$. tropicalis are not shown because they occurred virtually everywhere along the coastline

were assigned to breeding, non-breeding and idle colonies following Bester (1982). Identification of the species and assumed hybrids followed descriptions given by Bonner (1968), Condy (1978) and Anon. (2008). Age and sex classes of seals were categorised as: adult males, adult females, subadults and black pups (Condy 1978). Counts were made by moving on foot between and within sites, using binoculars when required (Table 1). Most counts were done by MNB, whereas PGR and JV surveyed the beaches in the northern sector from Ross Rocks Peninsula to Kent Crater and McNish Bay (Figure 1). The large area involved in the count and the time constraint (six full days on the island) prohibited repeated counting of all beaches to calculate errors of the estimates. Inaccessibility of breeding colony beaches and the presence of aggressive territorial males constrained counts at the island (Condy 1978, Kerley 1983, Bester et al. 2003). The intrinsic rate of population change was calculated using estimated pup numbers for the various years and the exponential function $N_{t}=N_{o} \mathrm{e}^{r t}$, following Caughley (1977), as previously applied to these fur seal populations (e.g. Kerley 1983, Bester et al. 2003, Hofmeyr et al. 2006). The intrinsic rate of population change $(r)$ was converted to a mean annual percentage change $\left[\%=\left(e^{r}-1\right) \times 100\right]$ following Caughley (1977). Total population size was estimated from the pup number:total population size ratio (1:4.8), following Kerley (1987).

\section{Fur seal A. gazella}

All adult males (territorial and idle males scored separately) and black pups were counted directly. No correction for undercounting was made. Only older black pups in the white-faced stage (Bonner 1968) and younger black pups with their mothers in attendance were assigned to this species when encountered singly or in small accessible groups. The black pups in the large exclusively $A$. gazella colony at Penguin Beach were assigned to this species. All other black pups were assigned to $A$. tropicalis (Bester et al. 2003).

\section{Fur seal A. tropicalis}

On rocky beaches, only adult territorial males were counted directly, whereas adult females and black pups were simply recorded as being either present or absent (Bester et al. 2003), because the pupping season had only reached the halfway stage (Hofmeyr et al. 2007). All fur seals were counted and classified that were present on the open vegetated areas behind landing beaches. Pup numbers were derived from an estimate based on a conversion factor (1:6.6) of territorial males:numbers of births (corrected for undercounting) at established breeding colony sites at Gough Island, following Bester (1980) and applied by Bester et al. (2003).

\section{Hybrids}

Hybrids other than adult males are very difficult to distinguish from individuals of these two species, therefore characteristically large (Kerley and Robinson 1987) phenotypically hybrid males (Condy 1978, Kerley 1983, Anon. 2008) were noted only, and in some cases their associations with other individuals.

\section{Results and discussion}

\section{Fur seal A. gazella}

The Antarctic fur seal breeding (pupping and mating) season had at the time of the survey drawn to a close (all pups born by mid-December; Hofmeyr et al. 2007) and the presence of only two confirmed breeding colony sites were found (Figure 1), the same as in 2001 (Bester et al. 2003). The first site, north of Boggel Beach, was a small mixed colony consisting of $A$. gazella males $(n=3)$ on vegetated areas with holdings of small aggregations of $A$. gazella and/or $A$. tropicalis females, Subantarctic fur seals of both sexes and one hybrid male. Only a few positively identified white-faced $A$. gazella pups and two black pups in close proximity to their $A$. gazella mothers (Table 1 ) were found there. A boulder beach, directly in front of the gently sloping vegetated area and which borders the sea, was crowded with Subantarctic fur seals of both sexes, $A$. gazella adult males $(n=10)$ and putative adult hybrid males $(n=14)$.

The second site contained a large, presumably pure breeding colony of $A$. gazella on a cobble/boulder beach in front, and to the sides of, the king penguin Aptenodytes patagonicus breeding colony at Penguin Beach. A total of 320 pups and 81 territorial males were counted over the entire beach (Table 1), more than the underestimated 163 pups (when the front part of the beach could not be viewed from close up) and the 38 territorial males over the entire beach (viewed from afar which precluded pup counts) in 2001. This study used the male:female ratio of $1: 10$ on crowded beaches at the peak of female numbers present for this species at South Georgia from McCann and Doidge (1987). The numbers of territorial males translated into a total of 380 pups for $2001 / 2002$ and 810 pups for 2008/2009, with a mean $r$ of $11.4 \%$ over the intervening years. These estimates of pup numbers are probably realistic, given the 
Table 1: Estimated numbers of territorial male A. gazella and $A$. tropicalis at Prince Edward Island during 17-22 December 2001 and 16-20 December 2008. Pup numbers for A. tropicalis are derived from counts of territorial males (after Bester 1980 and Bester et al. 2003)

\begin{tabular}{|c|c|c|c|c|c|c|c|c|}
\hline \multirow{3}{*}{ Locality } & \multicolumn{4}{|c|}{ A. gazella } & \multicolumn{4}{|c|}{ A. tropicalis } \\
\hline & \multicolumn{2}{|c|}{ Territorial males } & \multicolumn{2}{|c|}{ Pups } & \multicolumn{2}{|c|}{ Territorial males } & \multicolumn{2}{|c|}{ Pups } \\
\hline & 2001 & 2008 & 2001 & 2008 & 2001 & 2008 & 2001 & 2008 \\
\hline Vaalkop & 0 & 0 & 0 & 0 & 129 & 42 & 852 & 277 \\
\hline Vaalkop West-Kent Crater & 0 & 0 & 0 & 0 & 54 & 24 & 357 & 158 \\
\hline McNish Bay-Cave Bay & 38 & 81 & $163^{*}$ & 320 & $3^{*}$ & 176 & $20^{*}$ & 1161 \\
\hline Cave Bay & 0 & 0 & 0 & 0 & 106 & 172 & 700 & 1135 \\
\hline RSA Point-Boggel beaches & 0 & 0 & 0 & 0 & 148 & 218 & 977 & 1439 \\
\hline Boggel beaches & 15 & 29 & 24 & $10^{*}$ & 463 & 390 & 3056 & 2574 \\
\hline Boggel beaches-Albatross Beach & 0 & 0 & 0 & 0 & 383 & $192^{* *}$ & 2528 & $1267^{\star *}$ \\
\hline Albatross Beach & 0 & 0 & 0 & 0 & 111 & 127 & 733 & 838 \\
\hline Ross Rocks Peninsula & 0 & 0 & 0 & 0 & 582 & 576 & 3842 & 3802 \\
\hline Ross Rocks-Hope Stream & 0 & 0 & 0 & 0 & 93 & 96 & 614 & 634 \\
\hline Hope Stream Beach & 0 & 0 & 0 & 0 & 119 & 128 & 786 & 845 \\
\hline Hope Stream Beach-Vaalkop & 0 & 0 & 0 & 0 & 0 & 0 & 0 & 0 \\
\hline Total & 53 & 110 & 187 & 330 & 2191 & 2141 & 14465 & 14130 \\
\hline
\end{tabular}

* Underestimate

** Underestimate due to misty conditions

Table 2: Numbers of $A$. tropicalis pups and their mean annual percentage increase (see text) for beaches on Prince Edward Island between $1980 / 1981$ or $1981 / 1982,1987 / 1988,2001 / 2002$ and 2008/2009. Estimated pup numbers for 2001/2002 and 2008/2009 are derived from counts of territorial males (following Bester 1980 and Bester et al. 2003)

\begin{tabular}{|c|c|c|c|c|c|c|c|}
\hline \multirow{2}{*}{ Locality } & \multicolumn{4}{|c|}{ Pup numbers } & \multicolumn{3}{|c|}{$\begin{array}{c}\text { Mean annual percentage } \\
\text { increase/decrease }\end{array}$} \\
\hline & $\begin{array}{l}\text { Unadjusted for } \\
1981 \text { and } 1982\end{array}$ & $\begin{array}{c}\text { Unadjusted for } \\
1987 / 1988\end{array}$ & $\begin{array}{c}\text { Estimated } \\
2001\end{array}$ & $\begin{array}{l}\text { Estimated } \\
2008\end{array}$ & $\begin{array}{l}1982- \\
1987\end{array}$ & $\begin{array}{l}1987- \\
2001\end{array}$ & $\begin{array}{l}2001- \\
2008\end{array}$ \\
\hline Vaalkop & & & 852 & 277 & & & -14.8 \\
\hline Vaalkop West-Kent Crater & $5^{\star \star}$ & 12 & 357 & 158 & 15.7 & 27.4 & -11.0 \\
\hline Cave Bay & $7^{*}$ & 0 & 700 & 1135 & & & 7.1 \\
\hline RSA Point-Boggel beaches ${ }^{* * *}$ & $651^{* *}$ & 1300 & 4033 & 4013 & 12.2 & 8.4 & -0.1 \\
\hline Albatross Beach & $125^{\star \star}$ & 155 & 733 & 838 & 3.7 & 11.7 & 1.9 \\
\hline Ross Rocks Peninsula & $412^{*}$ & 1643 & 3842 & 3802 & 21.9 & 6.3 & -0.1 \\
\hline Ross Rocks-Hope Stream & $36^{*}$ & 85 & 614 & 634 & 13.1 & 15.2 & 0.5 \\
\hline Hope Stream Beach & $503^{*}$ & 561 & 786 & 845 & 1.6 & 2.4 & 1.0 \\
\hline Total & 2300 & 4186 & 11917 & 11702 & 12.7 & 9.3 & -0.3 \\
\hline
\end{tabular}

likelihood of pup undercounting that reaches $14.2-34.3 \%$ in Subantarctic fur seals (Bester et al. 2003) and the ratio of 'harem' male:final pup number that could be as high as 1:15 (Bonner 1968).

Only four territorial male $A$. gazella were found elsewhere, at South Cape on the rocky beach among $A$. tropicalis, with unidentified (by species) females viewed from afar. Idle adult males $(n=24)$ and numerous subadults, most undoubtedly male, were found singly or in small scattered groups, primarily in vegetated areas largely on other parts of the south-eastern sector of Prince Edward Island (present study), similar to the situation in 2001 (Bester et al. 2003).

The population is approximately 5280 individuals, after converting estimated pup numbers $(n=1$ 100; calculated from territorial male numbers in Table 1) to total population size, following Kerley (1983). Currently growing at a mean annual intrinsic rate of $11.0 \%$ at Penguin Beach since 2001 (present study) compared to the $16.2 \%$ between
1981/1982 and 2001/2002 (Kerley 1983, Bester et al. 2003), the population still appears to be in the rapid recolonisation phase (Roux 1987) of population growth, similar to its Marion Island counterpart (Hofmeyr et al. 2006). This increase is possibly augmented by individuals from elsewhere, most likely from South Georgia (Wynen et al. 2000, de Bruyn et al. 2007).

\section{Fur seal A. tropicalis}

Established breeding colony sites of Subantarctic fur seals at Prince Edward Island, primarily present in the eastern sector of the island from Hope Stream Beach to Cave Bay (Figure 1) in 2001, remained the same size in 2008 (Table 1). There was little increase in numbers (mean $r$ between $-0.1 \%$ and $+1.9 \%$ per year), the exception being sheltered Cave Bay which grew at a mean $r$ of $7.1 \%$ per year (Table 2). The range of the few small breeding colony beaches on the southern and western side of the island, 
mainly at South Cape and one west of Vaalkop, were extended to three small beaches between Cave Bay and Penguin Beach, three small beaches between Penguin Beach and South Cape, and one at Kent Crater Beach (Figure 1). On the other hand, the Vaalkop to Kent Crater areas showed declines of at least $11 \%$ per year (Table 2) when extrapolated from the numbers of territorial males counted. In addition, compared to 2001 when large numbers of males, mostly adult ( $n=11003)$, were found in idle colonies, primarily on vegetated areas behind access points from the sea as well as behind breeding colony beaches (Bester et al. 2003), much fewer ( $n=3778)$ were encountered there in 2008. This is an unexpected result as the bulk of censusing was done by the same field personnel involved in the 2001 survey (MNB and PGR), using the same censusing protocol and in the same time frame (mid-December). Environmental conditions such as weatherinduced departures (Bester and Rossouw 1994) may have contributed in part, but there were no signs (carcasses and skeletons) of excessive die-offs of adult males. This unexplained phenomenon was reported previously at the neighbouring Marion Island (de Bruyn et al. 2008).

The difficulty in censusing pups-of-the-season because of incomplete pupping season, aggressive territorial males, broken nature of the terrain, and major undercounts (Bester et al. 2003), culminated in the determining of the status of colonies (following Bester 1982) and counting only the conspicuous territorial males on breeding colony beaches (Table 1), then translating these counts into pup numbers (Bester et al. 2003). The estimated minimum pup number (excluding the inaccessible coastline; Figure 1), was approximately 14130 pups (Table 1), representing an estimated minimum total population of 67824 Subantarctic fur seals. This constitutes a decline in the mean annual intrinsic rate of natural increase from 9.3\% between 1987 and 2001 (Bester et al. 2003) to $-0.3 \%$ in 2008 . The Prince Edward Island population of Subantarctic fur seals has therefore increased past the relatively rapid recolonisation phase (Bester 1980, Roux 1987) to maturity, similar to the neighbouring Marion Island population (increasing at a mean annual rate of $2.0 \%$ ) which has entered the final maturation phase (Hofmeyr et al. 2006), characterised by minimal population growth (Roux 1987).

\section{Hybrids}

The presence of adult male $A$. tropicalis $(A t)$ and $A$. gazella $(A g)$, together with putative hybrid males at the northern Boggel beaches in this study, is similar to 2001 when Antarctic fur seal males $(n=9)$ and at least one assumed male hybrid were present. Spot checks in this study showed that all combinations of harems were found: species-specific harems, At male with both $A t$ and $A g$ females, $A t$ male with $A g$ female, $A g$ male with $A t$ and $A g$ females, $A g$ male and At females, with hybrid males in the mix as well. Except for the apparent large size of hybrids, typical of $\mathrm{Ag}$ bulls, the majority of male hybrids (13 of 14 phenotypic hybrids) tended to have more At characteristics, with an overall brown hue to nearly black, with a top notch of longer hair on the head, though not as prominent as that displayed by pure At males (Condy 1978, Kerley 1983).
Although phenotypic hybrids continue to be reported from neighbouring Marion Island (Hofmeyr et al. 2006), to date only one genotypic hybrid has been confirmed (Maboko 2008). Lancaster et al. (2007) suggest that reproductive isolating mechanisms that promote positive assortative mating and reduce the production of hybrid offspring among three congeneric species of fur seals at Macquarie Island culminated in a temporal decline in hybridisation. Furthermore, hybrids became virtually undetectable by the third generation of backcrossing (Lancaster et al. 2006). However, the pronounced sympatry of breeding individuals of both species in the present study and phenotypic hybrids that have persisted over time at the northern section of Boggel beaches justify an assessment of their level of hybridisation at Prince Edward Island.

Acknowledgements - We thank Leshia Upfold and Dave Whitelaw for additional observations during the December 2008 visit. Permission to visit Prince Edward Island was granted by the Prince Edward Islands Management Committee. We thank the Department of Environmental Affairs and Tourism, in particular Captain D Visser and the officers and crew of the FRS Africana for logistic support. WC Oosthuizen and PJN de Bruyn commented on an earlier version of this paper.

\section{References}

Anon. 2008. Note on hybrid southern fur seals genus Arctocephalus. In: Jefferson TA, Webber MA, Pitman RL (eds), Marine mammals of the world: a comprehensive guide to their identification - pinnipeds. Amsterdam: Elsevier. pp 340-341.

Bester MN. 1980. Population increase in the Amsterdam Island fur seal Arctocephalus tropicalis at Gough Island. South African Journal of Zoology 15: 229-234.

Bester MN. 1982. Distribution, habitat selection and colony types of the Amsterdam Island fur seal Arctocephalus tropicalis at Gough Island. Journal of Zoology, London 196: 217-231.

Bester MN, Rossouw GJ. 1994. Time budgets and activity patterns of sub-Antarctic fur seals at Gough Island. South African Journal of Zoology 29: 168-174.

Bester MN, Ryan PG, Dyer BM. 2003. Population numbers of fur seals at Prince Edward Island, Southern Ocean. African Journal of Marine Science 25: 549-554.

Bonner WN. 1968. The fur seal of South Georgia. Scientific Reports of the British Antarctic Survey 56.

Caughley G. 1977. Analysis of vertebrate populations. Brisbane: John Wiley \& Sons.

Condy PR. 1978. Distribution, abundance and annual cycle of fur seals (Arctocephalus spp.) on the Prince Edward Islands. South African Journal of Wildlife Research 8: 159-168.

de Bruyn PJN, Pistorius PA, Tosh CA, Bester MN. 2007. Leucistic Antarctic fur seal at Marion Island. Polar Biology 30: 1355-1358.

de Bruyn PJN, Bastos ADS, Eadie C, Tosh CA, Bester MN. 2008. Mass mortality of adult male Subantarctic fur seals: are alien mice the culprits? PLoS ONE 3: e3757. doi: 10.1371/journal. pone.0003757.

Hofmeyr GJG, Bester MN, Makhado AB, Pistorius PA. 2006. Population changes in Subantarctic and Antarctic fur seals at Marion Island. South African Journal of Wildlife Research 36: 55-68.

Hofmeyr GJG, Bester MN, Pistorius PA, Mulaudzi TW, De Bruyn PJN, Ramunasi AJ, Tshithabane NH, McIntyre T, Radzilani PM. 2007. Median pupping date, pup mortality and sex ratio of fur seals at Marion Island. South African Journal of Wildlife Research 37: 1-8.

Kerley GIH. 1983. Relative population sizes and trends, and 
hybridization of fur seals Arctocephalus tropicalis and A. gazella at the Prince Edward Islands, Southern Ocean. South African Journal of Zoology 18: 388-392.

Kerley GIH. 1987. Arctocephalus tropicalis on the Prince Edward Islands. In: Croxall JP, Gentry RL (eds), Status, biology and ecology of fur seals. Proceedings of an international symposium and workshop, Cambridge, England, April 1984. NOAA Technical Report NMFS 51: 61-64.

Kerley GIH, Robinson TJ. 1987. Skull morphometrics of male Antarctic and subantarctic fur seals Arctocephalus gazella and $A$. tropicalis and their interspecific hybrids. In: Croxall JP, Gentry RL (eds), Status, biology and ecology of fur seals. Proceedings of an international symposium and workshop, Cambridge, England, April 1984. NOAA Technical Report NMFS 51: 121-131.

Lancaster ML, Gemmell NJ, Negro S, Goldsworthy SD, Sunnucks P. 2006. Ménage à trios on Macquarie Island: hybridization among three species of fur seal (Arctocephalus spp.) following historical population extinction. Molecular Ecology 15: 3681-3692.

Lancaster ML, Bradshaw CJA, Goldsworthy SD, Sunnucks P. 2007. Lower reproductive success in hybrid fur seal males indicates fitness costs to hybridization. Molecular Ecology 16: 3187-3197.
Maboko VJ. 2008. Genetic diversity and hybridisation estimates of Arctocephalus tropicalis and A. gazella from Marion Island. MSc thesis, University of Pretoria, South Africa

McCann TS, Doidge DW. 1987. Antarctic fur seal, Arctocephalus gazella. In: Croxall JP, Gentry RL (eds), Status, biology and ecology of fur seals. Proceedings of an international symposium and workshop, Cambridge, England, April 1984. NOAA Technical Report NMFS 51: 5-8.

PEIMPWG (Prince Edward Islands Management Plan Working Group). 1996. Prince Edward Islands management plan. Pretoria: Department of Environmental Affairs and Tourism.

Roux J-P. 1987. Recolonization processes in the Subantarctic fur seal, Arctocephalus tropicalis, on Amsterdam Island. In: Croxall JP, Gentry RL (eds), Status, biology and ecology of fur seals. Proceedings of an international symposium and workshop, Cambridge, England, April 1984. NOAA Technical Report NMFS 51: 189-194.

Wynen LP, Goldsworthy SD, Guinet C, Bester MN, Boyd IL, Gjertz I, Hofmeyr GJG, White RWG, Slade R. 2000. Post-sealing genetic variation and population structure of two species of fur seal (Arctocephalus gazella and A. tropicalis). Molecular Ecology 9: 299-314. 